\title{
Maximization of Lactation Milk Production Without Decreasing Persistency*
}

\author{
C. Y. Lin ${ }^{1}$ and K. Togashi ${ }^{2}$ \\ ${ }^{1}$ Dairy and Swine Research and Development Centre, \\ Agriculture and Agri-Food Canada, Lennoxville, QC, Canada J1M 1 Z3 \\ ${ }^{2}$ National Agricultural Research Center for Hokkaido Region, \\ Hitsujigaoka 1, Toyohiraku, Sapporo, Japan 0628555
}

\begin{abstract}
This study treats each daily estimated breeding value (EBV) of the lactation as a separate trait to modify the lactation curve on a daily basis. Six selection strategies for improving lactation milk without decreasing persistency were compared: 1 ) index $\mathrm{I}_{\mathrm{R} 1}$, subject to the restriction of equal genetic gains at days in milk (DIM) 60 and 280,2$) \mathrm{I}_{\mathrm{R} 2}$, subject to the restriction of zero gain at DIM 60,3) desired gains index $\mathrm{I}_{\mathrm{d}}$, designed to increase lactation milk without altering the lactation curve, 4) index $\mathrm{I}_{\mathrm{u}}$, comprising lactation EBV and persistency without standardization, 5) index $\mathrm{I}_{\mathrm{w}}$, consisting of lactation $\mathrm{EBV}\left(\mathrm{EBV}_{\mathrm{L}}\right)$ and persistency with standardization, and 6) conventional selection on $\mathrm{EBV}_{\mathrm{L}}$ and used as a basis for comparison. Of the 6 selection strategies compared, $\mathrm{I}_{\mathrm{R} 2}$ yielded the greatest persistency, but achieved the smallest response in $\mathrm{EBV}_{\mathrm{L}}$, suggesting that it is impractical to increase persistency by inhibiting change in the peak yield. Index $\mathrm{I}_{\mathrm{u}}$ showed the same response in lactation milk as conventional selection on $\mathrm{EBV}_{\mathrm{L}}$, but resulted in the same decreased persistency. Although both $\mathrm{I}_{\mathrm{R} 1}$ and $\mathrm{I}_{\mathrm{d}}$ achieved constant persistency, the former produced a greater lactation response (669 $\mathrm{kg} \mathrm{EBV}$ ) than the latter (560 $\mathrm{kg} \mathrm{EBV})$. Thus, $\mathrm{I}_{\mathrm{R} 1}$ is a viable strategy for improving $\mathrm{EBV}_{\mathrm{L}}$ while holding persistency constant. None of the 6 selection strategies excelled in both lactation milk and persistency. Index $\mathrm{I}_{\mathrm{w}}$ appears to be a reasonable choice for improving both traits, although responses would depend on the relative economic importance of the 2 traits. Differential responses between $I_{u}$ and $I_{w}$ emphasize the need to weight the EBV of different traits by the inverse of their standard deviations in index construction when the EBV vary widely in variance. The general formula developed here provides a useful genetic means of modifying the
\end{abstract}

Received November 30, 2004.

Accepted March 3, 2005.

Corresponding author: C. Y. Lin; e-mail: clin@uoguelph.ca.

*Dairy and Swine Research and Development Centre Contribution No. 854. lactation curve by restricting differential genetic gains among different days of the lactation.

(Key words: lactation curve, persistency, restricted index)

Abbreviation key: $\mathbf{E B V}_{\mathbf{L}}=$ lactation EBV, $\mathbf{T D}=$ test-day.

\section{INTRODUCTION}

Modeling the shape of the lactation curves at the phenotypic or genetic level has been of great interest to dairy researchers for a variety of reasons. Nutritionists are interested in modeling the phenotypic curves of the lactating cows to formulate a balanced ration to meet their nutritional needs. Geneticists focus on modeling the individual genetic curves of the cows and estimating genetic parameters of the lactation curves to select for lactation yields or persistency (e.g., Shanks et al., 1981; Danell, 1982; Ferris et al., 1985; Batra et al., 1987; Jamrozik and Schaeffer, 1997; Grossman et al., 1999). Although the definition of persistency varies (Swalve and Gengler, 1999), it generally refers to the rate of decline in daily milk yield after the peak yield. A cow with a slower rate of decline after the peak yield is said to be more persistent. Persistent cows are more desirable because they are more efficient in roughage usage, suffer less metabolic stress due to high peak yield, and thus are more disease-resistant (Sölkner and Fuchs, 1987). Heritabilities of persistency and genetic correlations between first-lactation yield and persistency vary greatly depending on the measure of persistency used (Swalve and Gengler, 1999; Jakobsen et al., 2002). Togashi and Lin (2004) reported that current selection based on lactation EBV increased lactation milk yield at the expense of persistency, i.e., there was an undesirable association between lactation yield and persistency.

Macciotta et al. (2004) applied multivariate factor analysis of the correlation matrix of test-day (TD) records to derive 2 index scores, that were related to the rate of ascent to the lactation peak and the rate of decline after the peak (i.e., persistency). Genetic modi- 
fication of the lactation curves concerns the artificial redistribution of total lactation responses among different days or stages of the lactation. Togashi and Lin (2003) presented 2 equivalent selection procedures for simultaneous improvement of lactation milk and persistency: 1) index selection based on stage EBV, and 2) index selection based on random regression coefficients of the TD model. However, development of these 2 indices requires an a priori assumption of the lactation response and subjective distribution of genetic gains among different stages of the lactation. The purpose of this study was to compare different selection strategies for improving lactation milk yield without decreasing persistency and without requiring a priori assumption of the lactation response.

\section{MATERIALS AND METHODS}

\section{Current Selection on Lactation EBV}

The current selection for 305-d milk yield under TD random regression model is the sum of daily EBV from DIM 1 to 305,

$$
\mathrm{EBV}_{\mathrm{L}}=\sum_{t=1}^{305} \mathrm{EBV}_{t}=\hat{\boldsymbol{g}}^{\prime} \mathbf{1}
$$

where $\hat{\boldsymbol{g}}$ is a column vector containing the daily EBV from $t=$ DIM 1 to 305 and $\mathbf{1}$ is a unit column vector of order 305 . The lactation response to current selection on lactation $\mathrm{EBV}\left(\mathbf{E B V}_{\mathbf{L}}\right)$ is the sum of daily genetic gains $\left(\Delta G_{t}\right)$ from DIM 1 to 305 :

$$
\Delta G_{L}=\sum_{t=1}^{305} \Delta G_{t}=\mathbf{1}^{\prime} G \mathbf{1}\left(\bar{i} / \sigma_{L}\right)=\bar{i} \sigma_{L}=\bar{i} \sqrt{\mathbf{1}^{\prime} G \mathbf{1}}
$$

where $\sigma_{L}=\sqrt{\mathbf{1}^{\prime} G \mathbf{1}}, \bar{i}$ is selection intensity, and $\mathrm{G}$ is a $(305 \times 305)$ genetic covariance matrix on a daily basis.

In this study, persistency $(\mathrm{P})$ is defined as $\mathrm{P}=\mathrm{EBV}_{280} /$ $\mathrm{EBV}_{60}$. Single-trait selection for this criterion was reported to improve both lactational milk yield and persistency (Togashi and Lin, 2004). The criterion $\mathrm{EBV}_{\mathrm{L}}$ places equal weightings among daily EBV of the lactation, regardless of differences among daily EBV (Olori et al., 1998; Pool and Meuwissen, 2001). Selection based on $\mathrm{EBV}_{\mathrm{L}}$ tends to improve the lactation milk yield at the expense of persistency (Togashi and Lin, 2004). Thus, it is desirable to find optimal weightings for each daily EBV of the lactation to improve milk production without decreasing persistency.

\section{General Development of Restricted Index for Modification of the Lactation Curve}

Genetic modification of the lactation curve inherently implies the redistribution of the selection responses among different days or stages of the lactation. The treatment of each TD yield of the lactation as a separate trait makes it possible to combine these TD yields into an index to modify the lactation curve. The principle of the restricted selection index (Kempthorne and Nordskog, 1959) can be extended to alter the genetic response pattern of the lactation curve by maximizing the total lactational response in milk yield, subject to restricting the genetic gains at certain DIM.

Let the breeding goal be to maximize the lactation response subject to the restriction of genetic gains in certain days of the lactation curve. The restricted index (I) is the sum of weighted daily EBV from $t=$ DIM 1 to 305 .

$$
\mathrm{I}=\sum_{t=1}^{305} \mathrm{~b}_{\mathrm{t}} \mathrm{EBV}_{t}=\hat{g}^{\prime} b
$$

where $\hat{g}$ is a $(305 \times 1)$ column vector containing daily EBV ranging from DIM 1 to 305 , and $b$ is $(305 \times 1)$ column vector of index weights corresponding to $\hat{g}$. The net merit $(\mathrm{H})$ of the whole lactation to be maximized is the sum of daily genetic values from DIM 1 to 305:

$$
\mathrm{H}=\sum_{t=1}^{305} g_{\mathrm{t}}=g^{\prime} \mathbf{1}
$$

where $g$ is a column vector of daily genetic values $\left(g_{t}\right)$ ranging from $t=$ DIM 1 to 305. It follows from [2] and [3] that $\sigma_{I}^{2}=b^{\prime} G b, \sigma_{H}^{2}=\mathbf{1}^{\prime} G \mathbf{1}$, and $\sigma_{I H}=b^{\prime} G \mathbf{1}$.

Let $r$ be the number of TD yields restricted. The breeding goal is to maximize the lactation response [i.e., minimize $\left.\mathrm{E}(\mathrm{I}-\mathrm{H})^{2}\right]$ subject to the restriction of

$$
D^{\prime} b=\theta k
$$

where $k$ is a $(r \times 1)$ column vector of values (negative, zero, or positive) determined by the intended restrictions (zero, proportional, or both), $\theta$ is an unknown constant to be determined a posteriori, and $\mathrm{D}$ is a $(305 \times$ $r$ ) matrix containing the columns of $\mathrm{G}$ corresponding to the restricted DIM. The method of Lagrange multipliers gives,

$$
\begin{aligned}
f= & E(I-H)^{2}+\lambda^{\prime}\left(D^{\prime} b-\theta k\right)=b^{\prime} G b \\
& +\mathbf{1}^{\prime} G \mathbf{1}-2 b^{\prime} G \mathbf{1}+\lambda^{\prime}\left(D^{\prime} b-\theta k\right)
\end{aligned}
$$

where $\lambda$ is a $(r \times 1)$ vector of Lagrange multipliers. Differentiating the function $f$ with respect to $b, \lambda$, and $\theta$, and setting the partial derivatives equal to zero lead to the following set of equations: 


$$
\left[\begin{array}{ccc}
G & D & 0 \\
D^{\prime} & 0 & -k \\
0 & -k^{\prime} & 0
\end{array}\right]\left[\begin{array}{l}
b \\
\lambda \\
\theta
\end{array}\right]=\left[\begin{array}{c}
G \mathbf{1} \\
0 \\
0
\end{array}\right]
$$

The solution to equation [4] is,

$$
\begin{gathered}
b=\left[I-G^{-1} D\left(D^{\prime} G^{-1} D\right)^{-1} D^{\prime}\right] \mathbf{1} \\
+\frac{\mathbf{1}^{\prime} D\left(D^{\prime} G^{-1} D\right)^{-1} k}{k^{\prime}\left(D^{\prime} G^{-1} D\right)^{-1} k}\left[G^{-1} D\left(D^{\prime} G^{-1} D\right)^{-1} k\right] .
\end{gathered}
$$

It can be shown that $\sigma_{I}^{2}=\sigma_{I H}$ and $\Delta H=\bar{i} \sigma_{I}$. Expression [4] or [5] is a generalized form for constructing a restricted index to achieve maximum lactation response and manipulate daily genetic changes of the lactation curve at the same time. The presented procedure optimized the linear combination of the unrestricted BLUP subject to restrictions, whereas Quaas and Henderson (1976) imposed restrictions directly on the multitrait MME to obtain the restricted BLUP.

\section{Maximizing Lactation Milk Yield While Maintaining Persistency at a Constant Level}

The persistency measure $\mathrm{EBV}_{280} / \mathrm{EBV}_{60}$ indicates that the genetic responses at DIM 60 and 280 must increase at the same rate $\left(\Delta G_{60}=\Delta G_{280}\right)$ to achieve constant persistency. Restriction of $\Delta G_{60}=\Delta G_{280}$ is the same as imposing $\left(G_{60}^{\prime}-G_{280}^{\prime}\right) b=0$, where $G_{60}$ and $G_{280}$ refer to the 60th and 280th columns of $G$, respectively. Maximizing lactation response while maintaining a constant persistency is equivalent to minimizing $\mathrm{E}(\mathrm{I}-$ $\mathrm{H})^{2}$ subject to the restriction $\left(G_{60}^{\prime}-G_{280}^{\prime}\right) b=0$. The desired index can be obtained from equation [5] by setting $k=0$ and $D^{\prime}=\left(G_{60}^{\prime}-G_{280}^{\prime}\right)$ :

$$
b=\left[I-G^{-1} D\left(D^{\prime} G^{-1} D\right)^{-1} D^{\prime}\right] \mathbf{1}
$$

\section{Maximizing Lactation Milk Yield While Holding the Peak Yield Constant}

To maximize lactation response and hold the peak yield constant at the same time is equivalent to minimizing $\mathrm{E}(\mathrm{I}-\mathrm{H})^{2}$ subject to the restriction $G_{60}^{\prime} b=0$. The desired index that satisfies this restriction can be obtained from equation [5] by setting $k=0$ and $D^{\prime}=$ $G_{60}^{\prime}$ :

$$
b=\left[I-G^{-1} G_{60}\left(G_{60}^{\prime} G^{-1} G_{60}\right)^{-1} G_{60}^{\prime}\right] \mathbf{1}
$$

\section{Improvement of Lactation Milk Without Altering the Lactation Curve}

When the lactation curve is optimal, the breeding goal is to raise the level of production without changing the lactation curve. This would require the imposition of equal genetic gains on each day of the entire lactation curve $\left(\Delta G_{1}=\Delta G_{2}=\cdots=\Delta G_{305}\right)$, which can be rewritten as a proportional restriction of $\Delta G_{1}: \Delta G_{2}: \cdots: \Delta G_{305}=$ $1: 1: \cdots: 1$. The number of TD yields restricted is $r=305$ in this case. The index designed to fulfill this goal can be obtained by specifying $k=\mathbf{1}$ and $D=G$ in formula [5]. This leads to $b=\left(\mathbf{1}^{\prime} \mathbf{1} / \mathbf{1}^{\prime} G^{-1} \mathbf{1}\right) G^{-1} \mathbf{1}$, which further reduces to $b=G^{-1} \mathbf{1}$ as the scalar $\left(\mathbf{1}^{\prime} \mathbf{1} / \mathbf{1}^{\prime} G^{-1} \mathbf{1}\right)$ can be dropped.

Finally, the index designed to move the lactation curve upward without altering its shape is $\mathrm{I}_{\mathrm{d}}=\hat{g}^{\prime} G^{-1} \mathbf{1}$, which takes the same form as the desired gains index of Pesek and Baker (1969). Let $\Delta$ be a $(305 \times 1)$ vector of genetic responses for each DIM of the lactation. The desired gains index $\mathrm{I}_{\mathrm{d}}$ gives $\underline{\Delta}=G^{\prime} b\left(\bar{i} / \sigma_{I}\right)=G^{\prime} G^{-1} \mathbf{1}(\bar{i} /$ $\left.\sigma_{I}\right)=\mathbf{1}\left(\bar{i} / \sigma_{I}\right)$, thus achieving equal genetic gains for each DIM across the lactation, and a total lactation response of $305 \bar{i} / \sigma_{I}$ when summed across 305 DIM.

\section{Unweighted Linear Index for Improving Lactation EBV and Persistency}

Lactation EBV and persistency were linearly combined as follows:

$$
\begin{gathered}
\mathrm{I}_{\mathrm{u}}=E B V_{\mathrm{L}}+\frac{E B V_{280}}{E B V_{60}}=E B V_{\mathrm{L}} \\
+\left[\frac{\mu_{280}}{\mu_{60}}+\frac{1}{\mu_{60}} E B V_{280}-\frac{\mu_{280}}{\mu_{60}^{2}} E B V_{60}\right]
\end{gathered}
$$

where $\mu_{60}$ and $\mu_{280}$ are the means of EBV at DIM 60 and 280 , respectively.

The persistency $E B V_{280} / E B V_{60}$ was linearly approximated according to the Taylor series expansion (Mood et al., 1987). Because $\mu_{280} / \mu_{60}$ is a constant and can be dropped, the unweighted linear index $\left(\mathrm{I}_{\mathrm{u}}\right)$ becomes,

$$
\mathrm{I}_{\mathrm{u}}=E B V_{L}+\frac{1}{\mu_{60}} E B V_{280}-\frac{\mu_{280}}{\mu_{60}^{2}} E B V_{60}
$$

with variance 


$$
\begin{gathered}
\sigma_{I_{u}}^{2}=b^{\prime} G^{*} b=\left[1 \frac{1}{\mu_{60}}-\frac{\mu_{280}}{\mu_{60}^{2}}\right] \\
{\left[\begin{array}{ccc}
\sigma_{G_{L}}^{2} & \sigma_{G_{L \cdot 280}} & \sigma_{G_{L \cdot 60}} \\
\sigma_{G_{L \cdot 280}} & \sigma_{G_{280}}^{2} & \sigma_{G_{280 \cdot 60}} \\
\sigma_{G_{L \cdot 60}} & \sigma_{G_{280 \cdot 60}} & \sigma_{G_{60}}^{2}
\end{array}\right]\left[\begin{array}{c}
1 \\
1 / \mu_{60} \\
-\mu_{280} / \mu_{60}^{2}
\end{array}\right]}
\end{gathered}
$$

and the genetic responses for the 2 index traits are $\Delta^{*}=$ $G^{*} b\left(i / \sigma_{I_{u}}\right)$.

\section{Weighted Linear Index for Improving $\mathrm{EBV}_{\mathrm{L}}$ and Persistency}

Because of the large difference in variation between $\mathrm{EBV}_{\mathrm{L}}$ and persistency $(P)$, these 2 index traits were weighted by the inverse of their standard deviations (SD) as follows:

$$
\mathrm{I}_{\mathrm{w}}=\frac{E B V_{L}}{\sigma_{L}}+\frac{P}{\sigma_{P}}
$$

where

$$
\begin{gathered}
\sigma_{L}=\mathrm{SD} \text { of } \mathrm{EBV}_{\mathrm{L}} \text { and } \sigma_{P}= \\
\sqrt{\frac{1}{\overline{\mathrm{EBV}}_{60}^{2}} \sigma_{\mathrm{EBV}_{280}}^{2}-2 \frac{\overline{\mathrm{EBV}}_{280}}{\overline{\mathrm{EBV}}_{60}^{3}} \sigma_{\mathrm{EBV}_{60 \cdot 280}}+\frac{\overline{\mathrm{EBV}}_{280}^{2}}{\overline{\mathrm{EBV}}_{60}^{4}} \sigma_{\mathrm{EBV}_{60}}}
\end{gathered}
$$

It follows that $\sigma_{\mathrm{L}} \sigma_{\mathrm{P}} \mathrm{I}_{\mathrm{w}}=\sigma_{P} E B V_{L}+\sigma_{L} P$. Because $\sigma_{L}$ $\sigma_{P}$ are constants and can be dropped, this expression can be simplified further to $\mathrm{I}_{\mathrm{w}}=\sigma_{P} E B V_{L}+\sigma_{L} P$. When $P$ is linearly approximated, the weighted linear index $\mathrm{I}_{\mathrm{w}}$ becomes,

$$
\mathrm{I}_{\mathrm{w}}=\sigma_{P} E B V_{\mathrm{L}}+\sigma_{\mathrm{L}}\left(\frac{1}{\mu_{60}} E B V_{280}-\frac{\mu_{280}}{\mu_{60}^{2}} E B V_{60}\right)
$$

\section{Selection Strategies Compared}

Pool et al. (2000) fitted a random regression model with Legendre polynomials of order 4 ( 5 genetic random regression coefficients per animal) to estimate the genetic covariance matrix $(G)$ for first-lactation TD records of Dutch Holstein-Friesian cows. The estimates of their genetic covariance matrix and correlations are given in Table 1. This G matrix was used to compare the 6 selection strategies: 1) $I_{R 1}$, designed to maximize lactation response subject to the restriction of $\Delta G_{60}=$ $\Delta G_{280}$ (i.e., constant persistency), based on formula [6]; 2) $I_{R 2}$, designed to maximize the lactation response subject to the restriction of $\Delta G_{60}=0$, based on formula [7];
3) the desired gains index $I_{d}=\hat{g}^{\prime} G^{-1} \mathbf{1}$, designed to raise the overall production level without altering the lactation curve; 4) an unweighted linear index $\mathrm{I}_{\mathrm{u}}$ based on formula [8], designed to improve lactation milk and persistency simultaneously; 5) a weighted linear index $I_{w}$ based on formula [9], designed with the same purpose as $\mathrm{I}_{\mathrm{u}}$; and 6) conventional selection based on $\mathrm{EBV}_{\mathrm{L}}$, which was used for comparison.

\section{RESULTS AND DISCUSSION}

Selection responses in lactation EBV and persistency of the 6 indices are given in Table 2. Selection intensity was set to unity $(\bar{i}=1)$. The rate of decline $(\beta)$ in the lactation curve from DIM 60 to 280 is defined as $\beta=$ $\left(\Delta G_{60}-\Delta G_{280}\right) / 220$, which is the average of daily genetic gains during the $220 \mathrm{~d}$ of lactation between DIM 60 and 280. By this definition, persistency decreases when $\beta$ is positive, improves when $\beta$ is negative, and remains constant when $\beta$ is zero. As $\beta$ increases, the lactation curve between DIM 60 and 280 declines more steeply and persistency decreases. Therefore, the magnitude and sign of $\beta$ provides an objective way to compare genetic changes in persistency.

\section{Current Selection on $\mathrm{EBV}_{\mathrm{L}}$}

For persistency to improve (i.e., $\beta<0$ ), the genetic gain in daily yield at DIM 280 must increase at a greater rate than at DIM 60. Table 2 shows that current selection on $\mathrm{EBV}_{\mathrm{L}}$ would improve lactation milk yield by $672 \mathrm{~kg}$ EBV and decrease persistency $(\beta=1.06)$ because selection on $\mathrm{EBV}_{\mathrm{L}}$ produced a greater genetic gain at DIM 60 (2.28 kg EBV) than at DIM 280 (2.04 kg EBV).

\section{Restricted Indices}

Table 2 shows that index $\mathrm{I}_{\mathrm{R} 1}$, subject to the constraint of $\Delta G_{60}=\Delta G_{280}$, achieved constant persistency $(\beta=0)$ as intended, while producing a slightly smaller response in lactation milk ( $669 \mathrm{~kg}$ EBV) than conventional selection on $\mathrm{EBV}_{\mathrm{L}}(672 \mathrm{~kg} \mathrm{EBV})$. This result suggests that $\mathrm{I}_{\mathrm{R} 1}$ is a realistic strategy for improving lactation milk while holding persistency constant. Index $\mathrm{I}_{\mathrm{R} 2}$, designed to maximize lactation milk while holding peak production constant $\left(\Delta G_{60}=0\right)$, achieved the greatest persistency ( $\beta=-5.69)$ but the smallest response in lactation milk (120 kg EBV) among the 6 selection strategies compared (Table 2). In fact, Ferris et al. (1985) had previously reported that decreasing peak yield to improve persistency would decrease milk yield greatly. The sharp decrease in lactational response to selection on $\mathrm{I}_{\mathrm{R} 2}$ occurs because the genetic correlations among daily yields around the peak period or in midlactation are 
Table 1. Genetic variances (diagonal, bold), covariances (below diagonal), and genetic correlations (above diagonal) of test-day milk yields. ${ }^{1}$

\begin{tabular}{llllllllllll}
\hline DIM & 5 & 30 & 60 & 90 & 120 & 150 & 180 & 210 & 240 & 280 & 305 \\
\hline 5 & $\mathbf{5 . 7 2 6}$ & 0.789 & 0.570 & 0.446 & 0.381 & 0.350 & 0.337 & 0.333 & 0.334 & 0.343 & 0.347 \\
30 & 4.384 & $\mathbf{5 . 3 9 0}$ & 0.875 & 0.787 & 0.728 & 0.685 & 0.653 & 0.629 & 0.610 & 0.586 & 0.551 \\
60 & 3.290 & 4.900 & $\mathbf{5 . 8 1 7}$ & 0.953 & 0.917 & 0.882 & 0.850 & 0.818 & 0.788 & 0.741 & 0.684 \\
90 & 2.613 & 4.474 & 5.628 & $\mathbf{5 . 9 9 2}$ & 0.988 & 0.973 & 0.952 & 0.925 & 0.892 & 0.836 & 0.770 \\
120 & 2.223 & 4.116 & 5.383 & 5.891 & $\mathbf{5 . 9 2 7}$ & 0.998 & 0.998 & 0.986 & 0.959 & 0.902 & 0.834 \\
150 & 2.016 & 3.826 & 5.122 & 5.732 & 5.894 & $\mathbf{5 . 7 9 0}$ & 0.998 & 0.998 & 0.998 & 0.950 & 0.882 \\
180 & 1.918 & 3.602 & 4.871 & 5.539 & 5.800 & 5.802 & $\mathbf{5 . 6 5 2}$ & 0.998 & 0.998 & 0.986 & 0.919 \\
210 & 1.879 & 3.438 & 4.648 & 5.332 & 5.656 & 5.748 & 5.696 & $\mathbf{5 . 5 4 6}$ & 0.998 & 0.998 & 0.953 \\
240 & 1.878 & 3.324 & 4.459 & 5.123 & 5.477 & 5.636 & 5.678 & 5.637 & $\mathbf{5 . 5 0 7}$ & 0.998 & 0.984 \\
280 & 1.948 & 3.230 & 4.244 & 4.858 & 5.216 & 5.428 & 5.564 & 5.659 & 5.710 & $\mathbf{5 . 6 3 8}$ & 0.998 \\
305 & 2.068 & 3.189 & 4.114 & 4.704 & 5.066 & 5.291 & 5.450 & 5.596 & 5.761 & 6.030 & $\mathbf{6 . 2 2 0}$ \\
\hline
\end{tabular}

${ }^{1}$ Estimates on 335-d basis (Pool et al., 2000) were converted to 305-d basis according to the procedure of Togashi and Lin (2004).

highly positive (Table 1). Suppressing daily yields around the peak period would also suppress daily yields for the other DIM. Thus, it is not practical to inhibit daily yields around the peak period to increase persistency, although it might be better for the cow in terms of stress and disease resistance. The desired gains index $\mathrm{I}_{\mathrm{d}}$, designed to maintain the same lactation curve before and after selection, achieved a lactation response of 560 $\mathrm{kg}$ EBV and produced a lactation curve parallel to the original one. Although $I_{R 1}$ and $I_{d}$ realized the same goal of constant persistency $(\beta=0), \mathrm{I}_{\mathrm{R} 1}$ yielded a greater response in lactation milk (669 $\mathrm{kg}$ EBV) than $\mathrm{I}_{\mathrm{d}}(560$ $\mathrm{kg}$ EBV). Index $\mathrm{I}_{\mathrm{R} 1}$ imposed a restriction on DIM 60 and 280 only (i.e., restriction on 2 traits), whereas $I_{d}$ placed constraints on each day of the entire lactation (restriction on 305 traits), such that $I_{d}$ is subject to a greater restriction than $I_{R 1}$. As expected, the more severe the level of the restriction, the smaller the lactation response. Therefore, selection on $\mathrm{I}_{\mathrm{R} 1}$ is preferred over the desired gains index $I_{d}$ for improving lactation milk without decreasing persistency.

Table 2. Genetic responses (kg EBV) in lactation milk yield $\left(\triangle \mathrm{EBV}_{\mathrm{L}}\right)$ and rate of decline $(\beta)$ in lactation curve among the 6 selection strategies.

\begin{tabular}{lllll}
\hline Selection strategies $^{1}$ & $\Delta \mathrm{EBV}_{\mathrm{L}}$ & $\Delta G_{60}$ & $\Delta G_{280}$ & $\beta^{2}$ \\
\left.\hline${\text { Lactation EBV }\left(\mathrm{EBV}_{\mathrm{L}}\right)}\right)$ & 672 & 2.28 & 2.04 & 1.06 \\
$\mathrm{I}_{\mathrm{R} 1}\left(\Delta G_{60}=\Delta G_{280}\right)$ & 669 & 2.21 & 2.21 & 0 \\
$\mathrm{I}_{\mathrm{R} 2}\left(\Delta G_{60}=0\right)$ & 120 & 0 & 1.25 & -5.69 \\
$\mathrm{I}_{\mathrm{d}}$ (desired gains index) & 560 & 1.86 & 1.86 & 0 \\
$\mathrm{I}_{\mathrm{u}}$ (unweighted index) & 672 & 2.28 & 2.04 & 1.06 \\
$\mathrm{I}_{\mathrm{w}}$ (weighted index) & 509 & 1.28 & 2.23 & -4.34 \\
\hline
\end{tabular}

${ }^{1} \mathrm{I}_{\mathrm{R} 1}$ and $\mathrm{I}_{\mathrm{R} 2}$ are restricted indices with restrictions in parentheses. $\mathrm{I}_{\mathrm{d}}$ is a desired gain index with restriction of $\Delta G_{1}: \Delta G_{2}: \cdots: \Delta G_{305}=$ $1: 1: \cdots: 1 . I_{\mathrm{u}}$ and $\mathrm{I}_{\mathrm{w}}$ are, respectively, the unweighted and weighted linear indices comprising both lactation EBV and persistency.

${ }^{2} \beta=\left(\Delta G_{60}-\Delta G_{280}\right) / 220$ in $\mathrm{kg} / \mathrm{d}$, multiplied by 1000 .

\section{Unrestricted Linear Indices}

The unweighted linear index $\mathrm{I}_{\mathrm{u}}$ showed the same lactation response ( $672 \mathrm{~kg} \mathrm{EBV}$ ) as conventional selection on $\mathrm{EBV}_{\mathrm{L}}$ and carried the same decreased persistency ( $\beta=1.06$ ) (Table 2 ), indicating that including the persistency ratio in index $I_{u}$ had no impact on the rankings of animals by index $\mathrm{I}_{\mathrm{u}}$. This lack of impact occurred because the variance of $\mathrm{EBV}_{\mathrm{L}}\left(451,140 \mathrm{~kg}^{2}\right)$ overwhelmed the variance of the ratio $\mathrm{EBV}_{280} / \mathrm{EBV}_{60}(1.44$ $\mathrm{kg}^{2}$ ), so that $\mathrm{EBV}_{\mathrm{L}}$ played the dominant role in determining the index values of $I_{u}$.

Use of the weighted linear index $\mathrm{I}_{\mathrm{w}}$ resulted in a response in lactational milk yield of $509 \mathrm{~kg}$ EBV and achieved the second (after $\mathrm{I}_{\mathrm{R} 2}$ ) largest increase in persistency $(\beta=-4.34)$. The difference in response pattern between the unweighted $I_{u}$ and the weighted $I_{w}$ emphasizes the importance of weighting the EBV of different traits by the inverses of their standard deviations in index construction when large differences in variances exist. In addition, lactational yield and persistency were considered equally important economically in this study. For eventual applications, the relative economic importance of lactational yield and persistency must be considered in index construction. Information on relative economic weights between lactation milk and persistency is lacking in the literature. Proper determination of reasonable economic weights between these 2 traits is important so that selection strategies can be compared based on net merit $(\Delta \mathrm{H})$.

The modification of the lactation curves inherently implies the imposition of different restrictions on different days or parts of the lactation curve. The system of equations [4] developed in this study provides a generalized framework to maximize lactation milk yield while imposing different restrictions on particular DIM of the lactation period, without assuming prior knowledge of lactation genetic gains. In contrast, the study of Togashi 
and Lin (2003) required a priori assumption of lactation response and a subjective distribution of genetic gains among different stages of the lactation to modify the lactation curve for increased milk yield and persistency. Because selection intensity, selection goal, and environmental factors may change over time, the prespecified lactation response based on historical data could vary. Therefore, prior assumption of the realized lactation response to construct an index would not necessarily guarantee maximum improvement of lactation milk yield. This study treats each daily EBV of the lactation as an individual trait of the index compared with treating the EBV of each stage as a separate trait of the index (Togashi and Lin, 2003). Apparently, the present study has a better control of genetic change at each DIM of the lactation and offers an objective means of modifying the lactation curve without prior assumption of total lactation response and without subjective redistribution of genetic gains among different stages of the lactation.

\section{CONCLUSIONS}

Six selection alternatives for improving lactation milk without decreasing persistency were compared. Index $I_{R 1}$, subject to restriction of equal genetic gains at DIM 60 and 280, increased lactation milk by $669 \mathrm{~kg}$ EBV and maintained constant persistency. Index $\mathrm{I}_{\mathrm{R} 2}$, subject to the restriction of zero genetic gain at the peak period, achieved the greatest persistency, but yielded the smallest response in lactation milk. The desired gains index $I_{d}$ increased lactation milk by $560 \mathrm{~kg}$ EBV without altering the shape of the lactation curve. The unweighted index $I_{u}$ and conventional selection on $\mathrm{EBV}_{\mathrm{L}}$ showed identical responses in both lactation milk and persistency, suggesting that inclusion of persistency ratio in an index without accounting for trait variability did not change the ranking of the animals because the variance of $\mathrm{EBV}_{\mathrm{L}}$ overwhelmed the variance of persistency. When EBV of different traits with wide variations are combined into an index, they should be standardized. The results suggest that index $\mathrm{I}_{\mathrm{R} 1}$ is the method of choice for improving lactation milk while holding persistency constant, whereas the weighted index $I_{w}$ is a viable strategy for simultaneous improvement of lactation milk and persistency. The general formula developed here provides a useful tool for imposing different restrictions on different days of the lactation to modify the lactation curve.

\section{REFERENCES}

Batra, T. R., C. Y. Lin, A. J. McAllister, A. J. Lee, G. L. Roy, J. A. Vessely, J. M. Wauthy, and K. A. Winter. 1987. Multitrait estimation of genetic parameters of lactation curves in Holstein heifers. J. Dairy Sci. 70:2105-2111.

Danell, B. 1982. Studies on lactation yield and individual test-day yields of Swedish dairy cows. III. Persistency of milk yield and its correlation with lactation yield. Acta Agric. Scand. 32:93-101.

Ferris, T. A., I. L. Mao, and C. R. Anderson. 1985. Selecting for lactation curve and milk yield in dairy cattle. J. Dairy Sci. 68:1438-1448.

Grossman, M., S. M. Hartz, and W. J. Koops. 1999. Persistency of lactation yield: A novel approach. J. Dairy Sci. 82:2192-2197.

Jakobsen, J. H., P. Madsen, J. Jensen, J. Pedersen, L. G. Christensen, and D. A. Sorensen. 2002. Genetic parameters for milk production and persistency for Danish Holsteins estimated in random regression models using REML. J. Dairy Sci. 85:1607-1616.

Jamrozik, J., and L. R. Schaeffer. 1997. Estimates of genetic parameters for test-day model with random regression for yield traits of first lactation Holsteins. J. Dairy Sci. 80:762-770.

Kempthorne, O., and A. W. Nordskog. 1959. Restricted selection indices. Biometrics 15:10-19.

Macciotta, N. P. P., D. Vicario, C. D. Mauro, and A. Cappio-Borlina. 2004. A multivariate approach to modeling shapes of individual lactation curves in cattle. J. Dairy Sci. 87:1092-1098.

Mood, A. M., F. A. Graybill, and D. C. Boes. 1987. Introduction to the Theory of Statistics. McGraw-Hill, Singapore.

Olori, V. E., S. Brotherstone, W. G. Hill, and B. J. McGuirk. 1998. Fit of standard models of the lactation curve to weekly records of milk production of cows in a single herd. Livest. Prod. Sci. 58:55-63.

Pesek, J., and R. J. Baker. 1969. Desired improvement in relation to selected indices. Can. J. Plant Sci. 49:803-804.

Pool, M. H., L. L. G. Janss, and T. H. E. Meuwissen. 2000. Genetic parameters of Legendre polynomials for first parity lactation curves. J. Dairy Sci. 83:2640-2649.

Pool, M. H., and T. H. E. Meuwissen. 2001. Effects of random regression test-day models on EBVs and genetic trends in persistency. Interbull Bull. 27:184-188.

Quaas, R. L., and C. R. Henderson. 1976. Selection criteria for altering the growth curves. J. Anim. Sci. 43:221. (Abstr.)

Shanks, R. D., P. J. Berger, A. E. Freeman, and F. N. Dickinson. 1981. Genetic aspects of lactation curves. J. Dairy Sci. 64:1852-1860.

Sölkner, J., and W. Fuchs. 1987. A comparison of different measures of persistency with special respect to variation of test-day milk yields. Livest. Prod. Sci. 16:305-319.

Swalve, H. H., and N. Gengler. 1999. Genetics of lactation persistency. Occ. Publ. Br. Soc. Anim. Sci. 24:75-82.

Togashi, K., and C. Y. Lin. 2003. Modifying the lactation curve to improve lactation milk and persistency. J. Dairy Sci. 86:14871493.

Togashi, K., and C. Y. Lin. 2004. Efficiency of different selection criteria for persistency and lactation milk yield. J. Dairy Sci. 87:1528-1535. 